\title{
Urinary iodine excretion in pregnant women residing in areas with adequate iodine intake
}

\author{
F Azizi $^{1, *}$, A Aminorroya ${ }^{2}, M$ Hedayati ${ }^{1}, \mathrm{H}$ Rezvanian ${ }^{2}, M$ Amini $^{2}$ and $P$ Mirmiran ${ }^{1}$ \\ ${ }^{1}$ Endocrine Research Center, Shaheed Beheshti University of Medical Sciences, PO Box 19395-4763, Tehran, \\ Islamic Republic of Iran: ${ }^{2}$ Endocrine Research Center, Isfahan University of Medical Sciences, Tehran, \\ Islamic Republic of Iran
}

Submitted 19 December 2001: Accepted 25 June 2002

\begin{abstract}
Objective: Pregnancy is accompanied by profound alterations in thyroid economy and relative iodine deficiency. The aim of this study was to evaluate urinary iodine excretion of pregnant women in cities with adequate and more than adequate iodine intake.

Methods: A cross-sectional study was performed on schoolchildren and pregnant women in four cities in the Islamic Republic of Iran. Urinary iodine excretion was measured for 438 schoolchildren and 403 pregnant women. In addition, in Isfahan City, thyroid volume was measured by sonography for 30 pregnant women in each trimester of pregnancy and for 90 non-pregnant women who also had urinary iodine measurement.

Results: Median urinary iodine of schoolchildren was 31.2, 25.0, 20.2 and 19.3 $\mu \mathrm{g} / \mathrm{dl}$ in Rasht, Isfahan, Ilam and Tehran, respectively. Corresponding values for pregnant women were 33.8, 21.2, 19.0 and $18.6 \mu \mathrm{g} / \mathrm{dl}$. The percentage of pregnant women with urinary iodine below $20 \mu \mathrm{g} / \mathrm{dl}$ was 16, 45, 55 and 54, and below $10 \mu \mathrm{g} / \mathrm{dl}$ was 1, 7, 7 and 13, in Rasht, Isfahan, Ilam and Tehran, respectively. In Isfahan, urinary iodine was significantly decreased in the third trimester of pregnancy, compared with controls. Mean thyroid volume was $7.8 \pm 3.1 \mathrm{ml}$ and $7.8 \pm 2.8 \mathrm{ml}$ in pregnant and non-pregnant women, respectively.

Conclusion: Recommended values for dietary iodine through universal salt iodisation may not be adequate for pregnant women, and the specific problem of iodine and pregnancy should be considered further in the light of the latest recommendations.
\end{abstract}

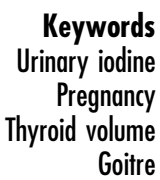

During pregnancy the thyroid is subject to increased demands, which is associated with a tendency to iodine deficiency ${ }^{1}$. In iodine-deficient areas, pregnancy therefore acts to disclose the underling iodine restriction with maternal and neonatal goitre formation and subsequent physical and intellectual impairment, which can easily be prevented by iodine supplementation ${ }^{2-5}$.

The recommended dietary allowance of iodine is that the ideal iodine intake should be $200 \mu \mathrm{g}$ per day for pregnant women ${ }^{6}$. However, some studies have shown that many women are iodine-deficient during pregnancy not only in iodine-deficient regions, but also in iodinesufficient areas $^{7}$. In Belgium ${ }^{8}$, south-west France ${ }^{9}$ and Denmark $^{10}$, the majority of pregnant women have urinary iodine below $100 \mu \mathrm{g} / \mathrm{dl}$.

In response to the reported incidence of iodine-induced thyrotoxicosis $^{11}$, the World Health Organization (WHO), the International Council for Control of Iodine Deficiency Disorders (ICCIDD) and the United Nations Children's Fund (UNICEF) have defined the adequate median urinary iodine as $100-200 \mu \mathrm{g} / 1^{12}$. They have pronounced levels of $>200-300 \mu \mathrm{g} / 1$ as more than adequate and those over $300 \mu \mathrm{g} / \mathrm{l}$ as excessive iodine intake. Median urinary iodine of $100 \mu \mathrm{g} / 1$ means that $50 \%$ of the population has urinary iodine level below $100 \mu \mathrm{g} / \mathrm{l}$. Although this recommendation may prevent the occurrence of iodine-induced thyrotoxicosis, it may be argued that with median urinary iodine of around $100 \mu \mathrm{g} / \mathrm{l}$ a few children and most pregnant and lactating women (whose recommended daily intake is $200 \mu \mathrm{g} / \mathrm{l}$ ) will remain deficient.

In the Islamic Republic of Iran, an effective national programme of dietary iodine supplementation via universal salt iodisation has resulted in a sustainable preventive programme for iodine deficiency disorders (IDD $)^{13}$, and the Eastern Mediterranean Office of WHO has announced Iran as an IDD-free country ${ }^{14}$. In order to evaluate the degree of iodine sufficiency in pregnant women, we studied urinary iodine levels during pregnancy in cities with adequate and more than adequate iodine intake. 


\section{Subjects and methods}

This cross-sectional study was performed in the cities of Rasht, Isfahan, Ilam and Tehran, between 1996 and 1998.

The Islamic Republic of Iran was known as an area of iodine deficiency. A national survey of goitre in 1989 showed that goitre existed in schoolchildren of most provinces with rates between 30 and $>70 \%{ }^{15}$ and it was estimated that 20 million people were at risk for iodine deficiency. The production and distribution of iodised salt, with $40 \mathrm{mg}$ of potassium iodide per $\mathrm{kg}$ of sodium chloride, began and education of policymakers, health personnel and public initiated in 1990. However, a rapid survey of iodised salt consumption showed that less than $50 \%$ of the population consumed iodised salt in 1993. Therefore, the first law requiring the mandatory iodisation of all salts for household use was proclaimed in 1994. Multiple rapid surveys of iodised salt consumption have demonstrated that, from 1994 onwards, more than 90\% of households consumed iodised salt ${ }^{13,16}$. Urinary iodine levels of schoolchildren are in the adequate to more than adequate range, according to WHO/ICCIDD criteria $^{12}$. Therefore, this study was performed 2 to 4 years after more than $90 \%$ of population consumed iodised salt.

\section{Study populations}

The study populations consisted of schoolchildren and pregnant women.

Four hundred and thirty-eight schoolchildren, 8 to 10 years of age, were randomly selected from primary schools of each city. There were 100, 102, 116 and 120 from Ilam, Rasht, Isfahan and Tehran, respectively. A morning sample of urine was obtained from each child for the measurement of urinary iodine.

A total of 403 healthy pregnant women, 90 to 116 in each city, who attended prenatal clinics and had no previous history of thyroid disease or medications that affect thyroid status, were sequentially admitted into the study. In addition, 90 age-matched non-pregnant women with similar excluding criteria who attended primary health clinics were chosen in Isfahan City. Morning urine samples were obtained from all pregnant and non-pregnant women for urinary iodine measurement. In Isfahan City, thyroid volume was also measured.

\section{Urinary iodine}

Urinary iodine analysis was performed using a digestion $\operatorname{method}^{17}$. The $2001 \mathrm{WHO} / \mathrm{UNICEF} / \mathrm{ICCIDD}$ criteria $^{12}$ were used to classify the urine content of iodine.

\section{Thyroid volume}

Thyroid volume was measured ultrasonically according to the method of Brunn et al. ${ }^{18}$, using a Dornier scanner (Dornier, Germany) with a $7.5 \mathrm{MHz}$ transducer. The volume of each lobe was calculated by the formula: length $(\mathrm{mm}) \times$ width $(\mathrm{mm}) \times$ thickness $(\mathrm{mm}) \times 0.000479$, and the result was expressed as $\mathrm{ml}$. The thyroid volume was the sum of the volume of both lobes (isthmus was not included).

\section{Statistical methods}

Statistical analysis was performed using SPSS for Windows (Version 9). Analysis of variance and $t$-tests were used to compare the findings.

\section{Results}

\section{Urinary iodine}

In pregnant women, the median of urinary iodine was 33.8, 21.2, 19.0 and $18.6 \mu \mathrm{g} / \mathrm{dl}$ in Rasht, Isfahan, Ilam and Tehran, respectively (Table 1 ). In Rasht, $84 \%$ of pregnant women had urinary iodine concentration $\geq 20 \mu \mathrm{g} / \mathrm{dl}$. However, only 46 to $55 \%$ of pregnant women in the other three cities had urinary iodine of more than $20 \mu \mathrm{g} / \mathrm{dl}$. Taken together, in the three cities of Isfahan, Ilam and Tehran, 4, 5, 18 and 24\% of pregnant women had urinary iodine of $<5,5-9.9,10-14.9$ and $15-19.9 \mu \mathrm{g} / \mathrm{dl}$, respectively. Median urinary iodine of schoolchildren was 31.2, 25.0, 20.2 and $19.3 \mu \mathrm{g} / \mathrm{dl}$ in Rasht, Isfahan, Ilam and Tehran, respectively.

\section{Trimesters of pregnancy}

In Isfahan, median urinary iodine was 20.5, 23.8 and $15.0 \mu \mathrm{g} / \mathrm{dl}$ in the first, second and third trimester of pregnancy, respectively, and $24.3 \mu \mathrm{g} / \mathrm{dl}$ in control

Table 1 Urinary iodine values of pregnant women and schoolchildren in four cities in Islamic Republic of Iran

\begin{tabular}{|c|c|c|c|c|c|c|c|c|}
\hline \multirow[b]{3}{*}{ City } & \multicolumn{8}{|c|}{ Urinary iodine concentration ( $\mu \mathrm{g} / \mathrm{dl})$} \\
\hline & \multicolumn{7}{|c|}{ Pregnant women } & \multirow{2}{*}{$\begin{array}{l}\text { Schoolchildren } \\
\text { (median) }\end{array}$} \\
\hline & Mean \pm SD & Median & $<5$ & $5-9.9$ & $10-14.9$ & $15-19.9$ & $\geq 20$ & \\
\hline Rasht & $34.4 \pm 14.1$ & 33.8 & $0^{*}$ & 1 & 7 & 8 & 84 & 31.2 \\
\hline Isfahan & $20.7 \pm 6.9$ & 21.2 & 4 & 3 & 19 & 19 & 55 & 25.0 \\
\hline Ilam & $20.6 \pm 9.8$ & 19.0 & 3 & 4 & 21 & 27 & 45 & 20.2 \\
\hline Tehran & $19.1 \pm 5.5$ & 18.6 & 4 & 9 & 15 & 26 & 46 & 19.3 \\
\hline
\end{tabular}

SD - standard deviation.

${ }^{*}$ Frequency distribution in per cent. 
Table 2 Urinary iodine values and thyroid volume of pregnant women during each of trimester of pregnancy and of control non-pregnant women in Isfahan City

\begin{tabular}{|c|c|c|c|c|}
\hline \multirow[b]{2}{*}{ Variable } & \multicolumn{3}{|c|}{ Trimester of pregnancy } & \multirow{2}{*}{$\begin{array}{c}\text { Non-pregnant } \\
\text { women } \\
(n=90)\end{array}$} \\
\hline & $\begin{array}{c}\text { First } \\
(n=30)\end{array}$ & $\begin{array}{l}\text { Second } \\
(n=30)\end{array}$ & $\begin{array}{c}\text { Third } \\
(n=30)\end{array}$ & \\
\hline $\begin{array}{l}\text { Age (years), mean } \pm S D \\
\text { Urinary iodine }(\mu \mathrm{g} / \mathrm{dl})\end{array}$ & $25.7 \pm 5.4$ & $25.7 \pm 4.9$ & $24.6 \pm 4.9$ & $27.5 \pm 7.8$ \\
\hline Mean \pm SD & $20.6 \pm 7.0$ & $23.3 \pm 6.3$ & $18.4 \pm 6.7$ & $23.7 \pm 7.6$ \\
\hline $\begin{array}{l}\text { Median } \\
\geq 20(\%)\end{array}$ & 20.5 & 23.8 & 15.0 & 25.5 \\
\hline $15-19.9(\%)$ & 17 & 23 & 17 & 13 \\
\hline $10-14.9(\%)$ & 23 & 10 & 23 & 8 \\
\hline$<10(\%)$ & 7 & 0 & 13 & 9 \\
\hline Thyroid volume $(\mathrm{ml})$, mean $\pm S D$ & $8.8 \pm 3.5$ & $7.0 \pm 2.5$ & $7.6 \pm 3.3$ & $7.8 \pm 2.8$ \\
\hline
\end{tabular}

SD - standard deviation

non-pregnant women (Table 2). Urinary iodine excretion was significantly decreased in the third trimester compared with control women $(P<0.02)$. However, there was no significant difference in urinary iodine excretion between the three trimesters of pregnancy. In non-pregnant women only $10 \%$ had urinary iodine less than the minimum adequate level $(100 \mu \mathrm{g} / \mathrm{dl})$, while $45 \%$ of pregnant women had values less than minimum recommended adequate levels during pregnancy $(200 \mu \mathrm{g} / \mathrm{dl})$.

\section{Thyroid volume}

Table 2 shows mean values and standard deviations of thyroid volume in pregnant and non-pregnant women. Mean thyroid volume was not significantly different in pregnant and non-pregnant women (7.8 \pm 3.1 vs. $7.8 \pm 2.8 \mathrm{ml}$ ). Volume of the thyroid in the first trimester was significantly greater than in the second trimester $(P<0.03)$; however, mean thyroid volume in all four groups did not exceed $9.0 \mathrm{ml}$.

\section{Discussion}

The findings of this study show that in the three cities of Isfahan, Ilam and Tehran, where schoolchildren have an adequate intake of iodine according to WHO/UNICEF/ ICCIDD criteria, almost half of pregnant women have urinary iodine excretion of less than $20 \mu \mathrm{g} / \mathrm{dl}$ and might be considered as iodine-deficient during pregnancy.

Previous studies have shown that not only pregnant women in iodine-deficient regions ${ }^{9,10,18}$ but also those residing in iodine-sufficient areas ${ }^{7,19}$ may suffer from iodine deficiency. In the United States, where an effective national programme for dietary iodine supplementation has been in place more than 80 years, the most recent study showed a median urinary iodine level of $145 \mu \mathrm{g} / \mathrm{dl}^{7}$. However, as many as $14.9 \%$ of women of child-bearing age and $6.7 \%$ of pregnant women had iodine excretion levels in the range of moderate to severe iodine deficiency, i.e. below $50 \mu \mathrm{g} / \mathrm{l}^{19}$.
The present study clearly shows that in Isfahan, Ilam and Tehran with adequate to more than adequate median urinary iodine, 18.6 to $21.2 \mu \mathrm{g} / \mathrm{dl}, 51 \%$ of pregnant women have urinary iodine less than recommended values for pregnancy and 9\% have urinary iodine less than $10 \mu \mathrm{g} / \mathrm{dl}$, which might be considered as severe iodine deficiency during pregnancy. In Rasht, where median urinary iodine was $33.8 \mu \mathrm{g} / \mathrm{dl}$ (excessive iodine intake according to new WHO criteria), 15.4 and $1.2 \%$ of pregnant women had urinary iodine below 20 and $10 \mu \mathrm{g} / \mathrm{dl}$, respectively.

The mean of thyroid volume is different in various geographic areas, from $14.3 \mathrm{ml}$ in Belgium ${ }^{2}$, to $16.2 \mathrm{ml}$ in Germany $^{3}$ and $26.4 \mathrm{ml}$ in Ireland ${ }^{4}$. From our data it is evident that the majority of pregnant women have normal thyroid volume in Isfahan. This finding also confirms the adequacy of iodine supplementation in this city. Thyroid volume was larger in the first trimester than in the second trimester and control women. This is in contrast to the study reported in Italy ${ }^{20}$.

In conclusion, the findings of this study call for further attention to iodine intake during pregnancy. Recommended values for dietary iodine through universal salt iodisation may not be adequate for pregnant women, and the specific problem of iodine and pregnancy should be considered further in the light of the latest recommendations.

\section{References}

1 Bauch K, Meng W, Ulrich FE, Grosse E, Kempe R, Schonemann $\mathrm{F}$, et al. Thyroid status during pregnancy and postpartum in regions of iodine deficiency and endemic goiter. Endocrinol. Exp. 1986; 20: 67-77.

2 Glinoer D, Nayer P, Delange F, Lemone M, Toppet V, Spehl $\mathrm{M}$, et al. A randomized trial for the treatment of mild iodine deficiency during pregnancy: maternal and neonatal effects. J. Clin. Endocrinol. Metab. 1995; 80: 258-69.

3 Liesenköpel W, Bogner U, Stach B, Grüters A. Earliest prevention of endemic goiter by iodine supplementation during pregnancy. Eur. J. Endocrinol. 1996; 134: 443-8.

4 Smyth PPA, Hetherton AMT, Smith DF, Radcliff M, O'Herlihy C. Maternal iodine status and thyroid volume during 
pregnancy: correlation with neonatal iodine intake. J. Clin Endocrinol. Metab. 1997; 82: 2840-3.

5 Glinoer D. Pregnancy and iodine. Thyroid 2001; 11: 471-81.

6 World Health Organization (WHO), United Nations Children's Fund (UNICEF), International Council for Control of Iodine Deficiency Disorders (ICCIDD). Progress Towards the Elimination of Iodine Deficiency Disorders (IDD). WHO Booklet. Geneva: WHO, 1999; 1-33.

7 Hollowell JG, Staehling NW, Hannon WH, Flanders DW, Gunter EW, Maberly GF, et al. Iodine nutrition in the United States. Trends and public health implications: iodine excretion data from National Health and Nutrition Examination Surveys I and III (1971-1974 and 1988-1994). J. Clin. Endocrinol. Metab. 1998; 83: 3401-8.

8 Glinoer D, De Nayer P, Bourdoux P, Lemone M, Robyn C, Van Steirteghem A, et al. Regulation of maternal thyroid during pregnancy. J. Clin. Endocrinol. Metab. 1990; 71 276-87.

9 Caron P, Hoff M, Bazzi S, Dufor A, Faure G, Ghandour I, et al Urinary iodine excretion during normal pregnancy in healthy women living in the southwest of France: correlation with maternal thyroid parameters. Thyroid 1997; 7: 749-54.

10 Nohr SB, Laurberg P, Borlum KG, Pedersen KM, Johannesen PL, Damm P, et al. Iodine deficiency in pregnancy in Denmark: regional variations and frequency of individual iodine supplementation. Acta Obstet. Gynecol. Scand. 1993 72: $350-3$.

11 Stanbury JB, Ermans AE, Boudroux P, Todd C, Oken E, Tonglet $\mathrm{R}$, et al. Iodine-induced hyperthyroidism occurrence and epidemiology. Thyroid 1998; 8: 83-100.

12 World Health Organization (WHO)/United Nations
Children's Fund (UNICEF)/International Council for Control of Iodine Deficiency Disorders (ICCIDD). Assessment of the Iodine Deficiency Disorders and Monitoring their Elimination. Report of Consultation, 4-6 May 1999; A Guide for Programme Managers, 2nd ed. WHO/NHD 01.1. Geneva: WHO, 2001

13 Azizi F, Sheikholesmai R, Hedayati M, Mirmiran P, Malekafzali H, Kimiagar M. Sustainable control of iodine deficiency in Iran. J. Endocrinol. Invest. 2002; 25: 409-13.

14 Regional Meeting for the Promotion of Iodized Salt in the Eastern Mediterranean, Middle East and North Africa Region, Dubai, United Arab Emirates, 10-21 April 2000.

15 Azizi F, Kimiagar M, Nafarabadi M, Yassai M. Current status of iodine deficiency disorders in the Islamic Republic of Iran. EMR Health Service J. 1990; 8: 23-7.

16 Azizi F. Success in prevention of iodine deficiency disorder in Iran [in Farsi]. Iran. J. Nucl. Med. 1995; 3: 1-3.

17 Dunn JT, Crutchfield ME, Gutekunst R, Dumm AN. Methods for Measuring Iodine in Urine. International Council for Control of Iodine Deficiency Disorders (ICCIDD)/United Nations Children's Fund (UNICEF)/World Health Organization (WHO) Publication. Geneva: WHO, 1993.

18 Brunn J, Blocjk U, Ruf J, Bos I, Kunze WP, Scriba PC. Volumetric der Schildrusenlppen mittens real-timesonographie. Dtsch. med. Wochenschr. 1981; 106: 1338-40.

19 Dunn JT. What's happening to our iodine [editorial]. J. Clin. Endocrinol. Metab. 1998; 83: 3398-400.

20 Glinoer D. The regulation of thyroid function in pregnancy: pathways of endocrine adaptation from physiology to pathology. Endocrine Rev. 1997; 18: 404-33. 